\title{
Self-Concept of Gifted Children Aged 9 to 13 Years Old
}

\author{
Jiannong Shi \\ Chinese Academy of Sciences \\ Capital Normal University
}

\section{Ying Li \\ Chinese Academy of Sciences \\ Shijiazhuang Post \& Telecommunication Technical College}

\author{
Xingli Zhang \\ Chinese Academy of Sciences \\ Capital Normal University
}

\begin{abstract}
Ninety-four gifted children and 200 nongifted children (aged 9 to 13 years old) were involved in the present study. Their self-concept was assessed by the Revised SongHattie Self-Concept Inventory (Zhou \& He, 1996). Academic self-concepts pertaining to abilities, school achievements, and grade concepts and nonacademic self-concepts pertaining to family, peers, body, and self-confidence concepts, as well as self-concept in general, were considered in the present study. The findings indicated that the development of self-concept in gifted children was different from that of nongifted children. Specifically, the self-concept scores in general of nongifted children increased from 11 to 13 years old, while those of gifted children decreased for the same age period. Both academic and nonacademic self-concepts are discussed in the present study.
\end{abstract}

Self-concept as an important construct in psychology has been widely studied (see Greenwald et al., 2002) since James (1890) raised it in his classic work The Principles of Psychology. Originally regarded as a unidimensional variable during the early years of study, self-concept is now considered a multidimensional and multilevel structure (Marsh, Richards \& Barnes, 1986). It is described as a perception of

Jiannong Shi is a Professor and Director of the Research Center for Supernormal Children at the Institute of Psychology, Chinese Academy of Sciences. Ying Li is a Lecturer of Shijiazhuang Post \& Telecommunication Technical College. Xingli Zhang is Assistant Professor of developmental psychology at the Institute of Psychology, Chinese Academy of Sciences.

Journal for the Education of the Gifted. Vol. 31, No. 4, 2008, pp. 481-500. Copyright (C2008 Prufrock Press Inc., http://www.prufrock.com 
one's attitude, feeling, and knowledge about one's talents, competence, appearance, and social acceptance (Byrne, 1986). Shavelson (1976) argued that one's experiences and the understanding and interpretation of these experiences underlined the formation of one's self-concept. In other words, a person's self-concept is gradually formed through interpersonal interaction and one's experience of being evaluated in social situations to become a multidimensional, multilevel structure or system.

Research pertaining to the development of self-concept and the relations between self-concept and academic performance of children in China has been extensively conducted in the last two decades. Xin and Hao (2003) suggested that there were interactions between children's self-concept and school achievement. Students with positive self-concepts had higher scores in achievement motivation, schooling involvement, and school achievement than students with negative self-concepts. According to Liu, Guo, and Wang (1991), self-concept and achievement motivation are the most important factors to children's school achievement, but self-concept plays a more direct and important role. For the development of children's self-concept, it was found that self-concept does not develop in an ascending straight line but has many peaks and valleys. It appears that self-concept declines from primary school to junior high school, increases during the adolescent years, declines again after graduation from university until middle age, followed by subsequent increase and a final, slow decrease after middle age (Freeman, 1992). The results of Marsh's (1994) study with the Self-Description Questionnaire (SDQ) administered to thousands of students aged 6-18 are persuasive. It was found that the scores of general self-concept and scores on most subscales began to decline during grades 7-9 and increase after grade 9. The development of self-concept appeared to be a U-shaped curve for early and midadolescent students, with relatively higher self-concepts in grade 7 , a decline in grades 8 and 9 , and an increase in grades 10 and 11 (Marsh, 1989). The results found later by Chinese scholars were similar to Marsh's, with the lowest point located between 13 and 14 years old (Zhou \& He, 1996).

In the field of giftedness, the importance of self-concept for gifted education is widely recognized. But the findings from different studies are still controversial. On the one hand, some studies 
found that gifted children normally had a higher level of self-concept (Elmore \& Zenus, 1992; Mulcahy, Wilgosh, \& Peat, 1991; Pyryt \& Mendaglio, 1994; Yong \& McIntyre, 1991). The general nonintellective factors, including self-concept of children, were investigated in one of our previous studies, and it was found that gifted children had higher levels of self-concept than that of nongifted children ( $\mathrm{Li}$ et al., 2004). In fact, some scholars argued that positive self-concept was the most important attribute for gifted children to ultimately realize their potential (Feldhusen \& Hoover, 1986). Consequently, how to improve the self-concept of gifted adolescents becomes the most important issue that gifted education has to face. On the other hand, Tong and Yewchuk (1996) did not find significant difference in self-concept between intellectually gifted and average students. Li and Shi (2005) reported that the difference in self-concept between gifted and nongifted adolescents was due to age. Although gifted adolescents had more positive academic self-concepts than a nongifted group in 1993, this finding was not duplicated in 2003 (Kong \& Zhu, 2005).

For the educational placement of gifted children in China, homogenous classrooms are predominant, although there are still other kinds of gifted programs with heterogeneous arrangements (Shi $\&$ Zha, 2000). It frequently has been reported that the gifted children enrolled in homogenous self-contained special classes achieve at much higher levels at the primary (Shi \& Zhai, 2004), secondary or high school level (Shen, 2006; Zhao, 2006), as well as at the university level (Xin, 1990). Vaughn, Feldhusen, and Asher (1991) completed a meta-analysis of nine experimental studies dealing with pull-out programs for gifted students in grades 1-9. Results indicated that pull-out programs in gifted education had significant positive effects on achievement, critical thinking, and creativity, but not on students' self-concept (Vaughn et al., 1991). However, while gifted children as a group have relatively higher self-concept levels than their average peers, the effect of homogenous self-contained special classes on gifted children's self-concept remains unclear. What happens within the gifted cohort, especially the developmental changes in self-concept of the gifted cohort, has been mostly neglected in gifted education in China. One purpose of this study, therefore, is to explore the developmental changes of self-concept within a gifted 
cohort in homogenous self-contained special classes, while comparing the results to a nongifted cohort. As it is, because self-concept is gradually formed through interpersonal interactions and the experience of being evaluated in social situations (Shavelson, 1976), it was interesting to see how the environment in self-contained classes affected the self-concept of the gifted.

According to Festinger's (1954) social comparison theory, the self-concept of an individual changes from situation to situation because the social reference framework is different in different situations. Chapman and McAlpine (1988) pointed out that the academic self-concept of gifted students declined when they were placed in a homogenous gifted class. This phenomenon was termed "big-fish-inlittle-pond effect" (BFLP effect) by Marsh and his colleagues (Marsh, Chessor, Craven, \& Roche, 1995). The BFLP effect was widely replicated in different countries and regions (Coleman \& Fults, 1982; Li \& Shi, 2005; Marsh \& Hau, 2003; Marsh, Hau, \& Craven, 2004; Zeidner \& Schleyer, 1998). On the other hand, culture is an encompassing social variable playing important roles in child development, and Chinese culture has always been regarded as very unique. Our hypothesis is that not only does the BFLP effect exist in gifted children in the Chinese culture, but the longer these gifted children stay in the gifted class, the more their self-concept will decline. So, the second purpose of this study is to test the universality of the BFLP effect in a typical Chinese culture and to see if the course of developmental changes of the Chinese gifted is similar to the course that was found in previous studies (Freeman, 1992; Marsh, 1989; Zhou $\& \mathrm{He}, 1996)$. In other words, this research allows us to test the universality of the BFLP effect across intellectual levels.

Enrollment into self-contained gifted classes is very competitive. For readers' better understanding of the typical gifted self-contained class in China, and in particular, Beijing, the setting for this study, it is necessary for us to describe the admission procedure. The admission test is administered to nominated 6-year-old children at the primary level and 10-year-old children at the secondary level once every 2 years. The candidates come from all over the metropolitan city. When the gifted class is open for admission, roughly 1,400 candidates apply and take the admission test at the primary and secondary level respectively. But only 30-35 (less than 3\%) of them will be 
accepted. The candidates are nominated by their teachers or parents according to their performances in their own schools or kindergartens. Then, the candidates for the secondary gifted program have to take part in a group intelligence test (a kind of general intelligence test; Jin, 1996) and subject tests of math, Chinese, and English, while candidates for the primary program have to take part in a nonverbal intelligence test (another group intelligence test). After the preliminary test session, the top 200 (about 15\%) candidates of each cohort are invited for the second session; during the second session, the candidates for the primary and secondary programs are further tested with computerized cognitive tests, including analogical reasoning, mental rotation, working memory, speed of information processing, and so forth. The test lasts for about 40 minutes for primary candidates and 60 minutes for secondary candidates (breaks are allowed for young children). After the second session, about 50 (25\%) of the top candidates from each cohort are invited to participate in the third session, a classroom observation. These children will be arranged into two classes to take part in real classroom instruction activities. Teachers with extensive experience with gifted education will be invited to teach these children and give an evaluation on each child. The classroom observation session lasts 1 and 2 weeks for primary and secondary programs, respectively. After this session, about 30 to 35 children from each cohort will finally be admitted to the self-contained gifted class. The rest of the children will be assigned to parallel classes at the same school with gifted programs.

The self-contained gifted class is involved in acceleration, a typical educational pattern for intellectually gifted children in China, especially in Beijing, its capital city. At the primary level, a 6-year-old child enrolled in the gifted program will finish his or her primary school education within 4 years, 2 years shorter than the regular primary school education program (Shi \& Zha, 2000; Shi \& Zhai, 2004). At the secondary level, the gifted 10 -year-old child will finish his or her junior and senior high school education within 4 years, again 2 years shorter than the regular program at the secondary level, where students have 3 years of junior and 3 years of senior high education respectively (Zhou \& Zha, 1986). Radical acceleration being a common phenomenon in China's gifted education, another purpose of this study is to see what the development of self-concept of 
these academically accelerated gifted children is like; in other words, is their self-concept accelerated together with their academic performance? Does their self-concept develop in line with their academic age or with their chronological age? Again based on the conception of self-concept that previous experience plays an important role in its formation, gifted individuals have many successful experiences in academic performance (Zhang, He, \& Wang, 1994), which is likely to foster a more positive academic self-concept. In a cross-cultural study, it was found that self-concept has a positive correlation with IQ: the higher the students' IQ, the higher the level of self-concept the students had (Chen, Peters, \& Moenks, 1997). So, our second hypothesis is that gifted children will have a higher level of self-concept than their same-age peers who are nongifted.

\section{Methods}

\section{Subjects}

In the present study, 33 nine-year-old (male $n=20$, female $n=13$ ), 30 eleven-year-old (male $n=21$, female $n=9$ ), and 31 thirteen-year-old (male $n=23$, female $n=8$ ) gifted children were the subjects of the study. A group of nongifted children, 50 eleven-year-olds (male $n=$ 25 , female $n=25$ ) and 139 thirteen-year-olds (male $n=77$, female $n=$ 62), served as the comparison. Nine-year-old nongifted children were not included because they could not fully understand the description in the questionnaire. A summary of their ages is listed in Table 1.

\section{Instrument}

A Chineseversion of the Revised Song-Hattie Self-Concept Inventory by Zhou and $\mathrm{He}$ (1996) was employed in the present study. This selfconcept scale is a 6-point Likert scale of 35 items divided into seven aspects (e.g., competence, school performance, grade, family, peer, body, and self-confidence). The Revised Song-Hattie Self-Concept Inventory has both good validity and good test-retest reliability (Zhou \& He, 1996). 
Table 1

Age Summary of Subjects

\begin{tabular}{ccccc}
\hline \multirow{2}{*}{ Group } & \multicolumn{2}{c}{ Gifted Children } & \multicolumn{2}{c}{ Nongifted Children } \\
\cline { 2 - 5 } & Mean Age & $S D$ & Mean Age & $S D$ \\
\hline 9 year olds & 9.02 & 0.43 & - & - \\
11 year olds & 11.04 & 0.52 & 10.74 & 0.31 \\
13 year olds & 13.15 & 0.38 & 13.0 & 0.28 \\
\hline
\end{tabular}

Note. Nine-year-old nongifted children were not included in the sample because they could not fully understand the questionnaire.

\section{Procedure}

The Revised Song-Hattie Self-Concept Inventory was administered to all subjects in their classrooms. All children finished answering questions within 40 minutes. No time limit was imposed.

\section{Results}

\section{Descriptive Statistics}

General descriptive statistics were calculated, and the scores of the gifted and the nongifted groups on the seven aspects of self-concept, as well as on academic, nonacademic, and total self-concept, are listed in Table 2.

\section{MANOVA Results}

The present study was designed with 3 independent variables (ages $[9,11,13$ for the gifted group and ages 11 and 13 for the nongifted group], gender [male, female], and student type [gifted, nongifted]) and 7 dependent variables (competence, school performance, grade, family, peer, body, and self-confidence). In order to detect the main effects of independent variables, a multivariate analysis of variance (MANOVA) was used. The results indicated that neither age nor 


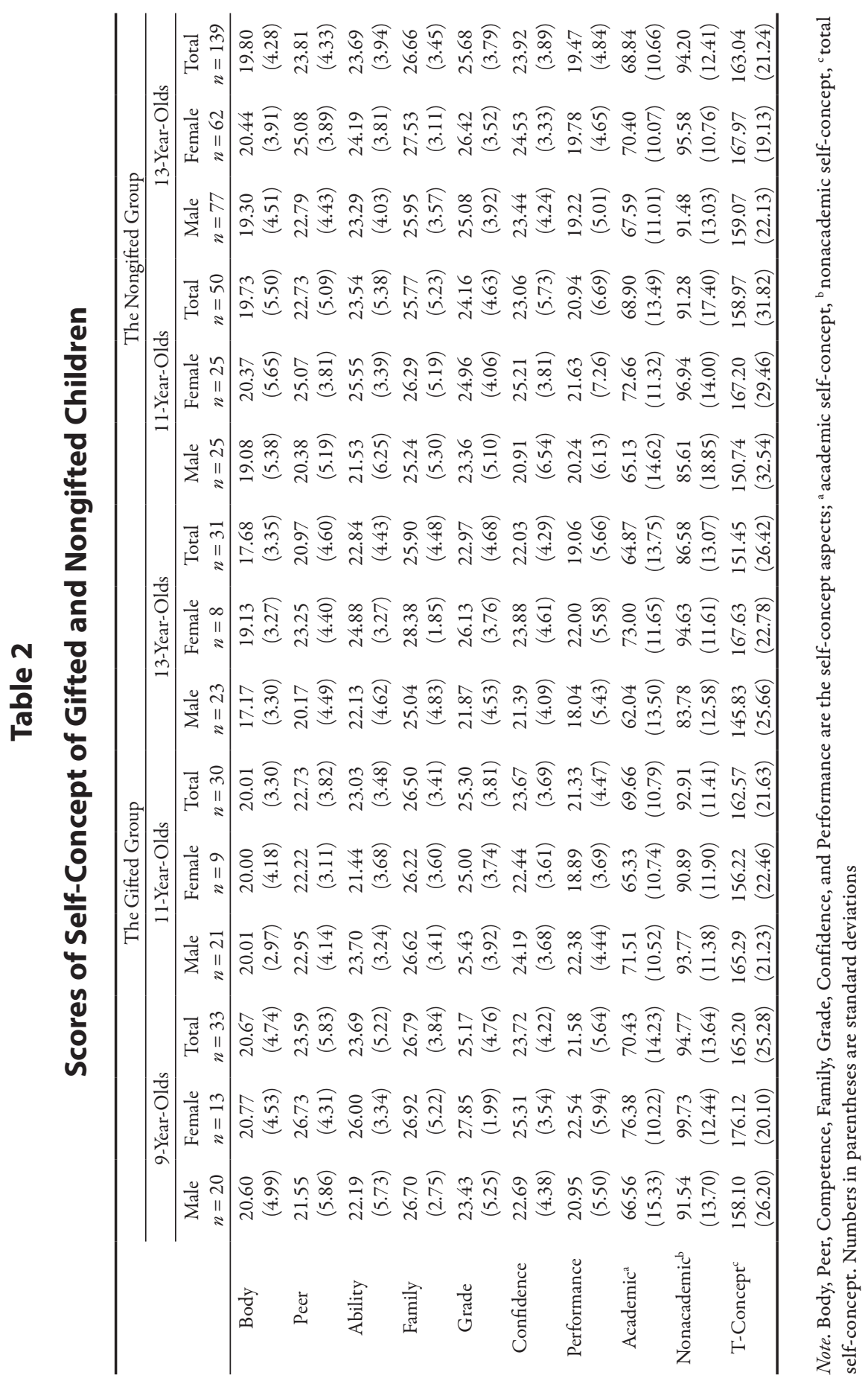


student type is generally significant, but gender is very significant, $F(7,267)=5.55, p=0.000$. The interaction between student type and gender is not significant, nor is the triplet interaction among age, student type, and gender, but the interaction between age and student type, $F(7,267)=1.93, p=0.065$, and between age and gender, $F(14,534)=1.66, p=0.061$, are marginally significant. In order to detect the interaction between age and student type and the interaction between age and gender, MANOVA with age and student type as independent variables and gender as a covariate and then age and gender as independent variables and student type as a covariate were run. The results indicated that when gender was controlled as a covariate, the interaction between age and student type became significant, $F(7,271)=2.53, p=0.015$; when student type was controlled as a covariate, the interaction between age and gender became significant, $F(14,540)=1.93, p=0.021$. In both conditions, the main effects age and student type were still not significant, while the main effect gender was constantly significant. In the condition of significant interaction between age and student type, it appears that the slight decline of self-concept in gifted children and the slight increase of self-concept in nongifted children are significant. In other words, it can be assumed that the self-concept of gifted children declined with age, while the self-concept of nongifted children increased with age. In the condition of significant interaction between age and gender, the changes in self-concept in boys and girls across three examined ages are significantly different.

The general MANOVA results also were calculated to detect the effects of three independent variables and their interactions on each of the 7 dependent variables. The results indicated that neither age nor student type had any significant effect on all 7 aspects of selfconcept, while gender played a significant role on self-concept of peer, $F(1,273)=26.45, p=0.000$; competence, $F(1,273)=12.56$, $p=0.000$; grade, $F(1,273)=16.28, p=0.000$; and self-confidence, $F(1,273)=11.03, p=0.001$; and a marginal role on family self-concept, $F(1,273)=3.61, p=0.059$. A significant interaction of age and student type on grade self-concept was found, $F(1,273)=4.40$, $p=$ 0.037 . Significant triplet interactions among age, gender, and student type on self-concept of peer, $F(1,273)=4.67, p=0.033$; competence, $F(1,273)=8.33, p=0.004$; self-confidence, $F(1,273)=7.17$, 
$p=0.008$; and performance, $F(1,273)=5.53, p=0.019$, were also found. It appears that the children's self-concept in these aspects were influenced by age, gender, and intellectual level, but the interaction mechanism was complicated.

Finally, to give an overall picture of the academic and the nonacademic self-concept, as well as the whole self-concept, a MANOVA was run with age, gender, and student type as independent variables and academic self-concept (sum of competence, grade, and performance self-concepts), nonacademic self-concept (sum of body, peer, family, and self-confidence self-concepts) and the whole self-concept (sum of all 7 aspects) as dependent variables. The results indicated that the effect of gender on academic self-concept, nonacademic selfconcept, and whole self-concept was significant, $F(1,273)=10.90$, $p=0.001, F(1,273)=14.68, p=0.000$, and $F(1,273)=12.75, p=$ 0.000 , respectively. No significant effects for age and student type nor interactions between age and gender, age and student type, and gender and student type were found, but the triplet interaction among age, gender, and student type on academic, nonacademic, and whole self-concept were significant, $F(1,273)=7.99, p=0.005, F(1,273)=$ $4.81, p=0.029$, and $F(1,273)=5.96, p=0.015$, respectively.

\section{Self-Concept Across Age Groups}

The results of an independent sample $t$ test indicated that for the nongifted children, self-concept scores of the 11-year-old group were slightly higher than those of the 13-year-old group, but only differences on grade self-concept, $t=2.08, p=0.041$, was significant. For the gifted children, a post hoc analysis of the age groups revealed that no significant differences were found on any aspects of self-concept between the 9-year-old group and the 11-year-old group, although the scores of the 9-year-old group were slightly higher. Significant or marginally significant differences were found on body, peer, and grade self-concepts between the 9 - and the 13-year-olds $(p=0.003, p=$ 0.033 , and $p=0.051$, respectively). Significant differences were found on body and grade self-concept between the 11- and the 13-year-old group ( $p=0.021$ and $p=0.044$, respectively); the younger group scored higher than the older group on all aspects. In general, there were no significant differences between 11 - and 13-year-old nongifted 
children, although the scores of the older group were slightly higher than those of the younger group on academic self-concept, nonacademic self-concept, and whole self-concept. For the gifted group, the scores of the 11-year-old group were slightly lower than those of the 9 -year-old group on academic, nonacademic, and whole self-concept, while the scores of the 13-year-old group were slightly lower than those of the 11-year-old group $(p=0.056)$ and significantly lower than the 9 -year-old group ( $p=0.012)$ on nonacademic self-concept; similarly, the scores of the 13-year-old group were slightly lower than those of the 11-year-old group on whole self-concept $(p=0.081)$. When the scores of the 9-and 13-year-old groups were compared, the differences became greater, and there were significant differences on whole self-concept $(p=0.028)$.

\section{Self-Concept in Gifted and Nongifted Children}

In order to explore the different aspects of self-concept of gifted and nongifted children with the same ages, an independent sample $t$ test was employed and analyzed for the 11- and 13-year-old groups. For the 11-year-old group, the results indicated no significant differences, although, in most aspects, the gifted children's mean scores were slightly higher than the nongifted children. However, for the 13-year-old cohort, the scores of the nongifted children were higher than those of the gifted children on all aspects, with significant differences in self-concepts of body, $t=2.595, p=0.01$; peer, $t=3.266$, $p=0.001$; grade, $t=3.01, p=0.005$; and self-confidence, $t=2.405$, $p=0.017$, but there were no significant differences on competence, family, and performance. Generally, for the 11-year-old cohort, the scores of the gifted group were higher than those of the nongifted group but differences were not significant; for the 13-year-old cohort, the scores of the gifted group were lower than those of the nongifted group, and the differences on nonacademic self-concept and whole self-concept were significant, $t=3.06, p=0.03$ and $t=2.62, p=$ 0.01 , respectively. There was also a marginal difference in academic self-concept, $t=1.77, p=0.078$. 


\section{Gender Differences}

The results of an independent sample $t$ test indicated that for both the gifted and the nongifted group girls' scores on all aspects of selfconcept were higher than the boys' scores. In the nongifted 11-yearold group, significant gender differences were found on self-concept of peer, competence, and self-confidence, $t=3.64, p=0.001 ; t=$ $2.83, p=0.008$; and $t=2.84, p=0.007$, respectively. In the nongifted 13-year-old group, significant differences on self-concept of peer, family, and grade, $t=3.19, p=0.002 ; t=2.74, p=0.007$; and $t=2.12, p=0.035$, respectively, were found. In the gifted 9-year-old group, significant gender differences were found on peer, $t=2.735$, $p=0.01$; competence, $t=2.165, p=0.038$; and grade, $t=2.888, p=$ 0.007 . Similarly, significant differences were found on performance self-concept, $t=2.07, p=0.048$, in the gifted 11-year-old group and on grade, $t=2.78, p=0.01$, and performance, $t=2.38, p=0.024$, in the gifted 13-year-old group. In general, significant gender differences on academic and nonacademic self-concept were found in the nongifted 11-year-old group, $t=2.04, p=0.047$; and $t=2.41, p=$ 0.02 , respectively, and marginal difference on whole self-concept, $t=$ $1.88, p=0.067$, significant differences on nonacademic and whole self-concept in the nongifted 13-year-old group, $t=2.96, p=0.004$ and $t=2.50, p=0.013$, respectively. For the gifted groups, there were significant gender differences on academic and whole self-concept in the 9-year-old group, $t=2.03, p=0.051$ and $t=2.11, p=0.044$, respectively, no significant difference in the 11-year-old group, and significant differences on academic, nonacademic, and whole selfconcept in the 13-year-old group, $t=2.04, p=0.050 ; t=2.14, p=$ 0.041 ; and $t=2.13, p=0.042$.

\section{Discussion}

\section{Self-Contained Gifted Class and Self-Concept of Gifted Children}

A hypothesis of the present study is that the longer a gifted child studies in a homogenous gifted class, the more likely his or her self-concept will decline. This hypothesis seems to be partly supported by the 
findings in the present study. It is partly supported because the scores of self-concept in all aspects decline from 9-year-olds to 13-year-olds, with no significant differences between 11 - and 9-year-olds and some significant differences between 13-and 11-year-old gifted children. According to comparison theory (Festinger, 1954) and the findings of other studies on BFLP effect, the academic self-concept should be mostly influenced by placement into a self-contained special program because it is more competitive academically for gifted children in a homogenous class than in a mixed regular class. This effect is reflected in the grade self-concept of 13-year-old gifted children being significantly lower than that of both the 11-year-old and the 9-year-old group. Also the performance and competence self-concepts of the oldest group are lower than those of the two younger groups. But the decline in nonacademic self-concept in general may not be explained by the BFLP effect. Rather, it may reflect the general developmental tendency for self-concept to decline in children during this period (Marsh, 1989; Zhou \& He, 1996). It is obvious that, in order to further test the BFLP effect of self-contained special gifted class on the self-concept of gifted children, it is necessary to conduct a longitudinal study with a sample of gifted children for several years to see if their self-concept changes. Comparison studies on self-concept with gifted children in self-contained gifted classes and gifted children in regular mixed class also are crucial for testing the BFLP theory.

\section{Comparison of Gifted and Nongifted Children}

Our second hypothesis of this study is that gifted children will have a higher level of self-concept than nongifted children. However, this hypothesis is rejected by the results of the present study. The selfconcept of 11-year-old gifted children in every aspect and as a whole is slightly higher than that of the nongifted children of the same age, but the differences are not significant. One possible reason is that the group of 11-year-old gifted children was newly admitted to the program. They might be still influenced by their experience of success in previous mixed regular classes and may not have enough experience being challenged in competitive special gifted programs. Two years later, however, for the 13-year-old cohort, the self-concept of gifted 
children is lower than that of nongifted children in all aspects, with significant differences in self-concept of body, peer, grade, and selfconfidence. This result can be explained with the BFLP effect. Before they were enrolled into the gifted class, their competence and school achievement were superior to their classmates in mixed classes. The superiority of their competence and achievement enhanced their self-confidence. However, when they were enrolled in homogenous self-contained gifted classes, the reference framework changed. Equally gifted or more gifted individuals surround every gifted child. After 2 years of study in the gifted program, their previous feeling of superiority no longer exists. Meanwhile, they will soon take part in university entrance examination 3 or 4 years earlier than nongifted high school graduates. The obvious pressure may pull down their selfconcept, too. As a result, their self-concept is lower than their sameaged nongifted peers.

Gifted children's self-concept continues to decline from 9 to 13 years old, lending support to our first hypothesis. Worse still, their self-concept is lower than that of the nongifted children, which rejects our second hypothesis. This result is an important lesson for the educator of the gifted: When gifted children's school performance is accelerated, their self-concept may not accelerate simultaneously. In fact, their self-concept declines when their school achievement increases. Considering self-concept is very important for personality development in students (Gao, 2000), helping gifted children in selfcontained homogenous classes establish a positive self-concept is as important as enhancing their academic achievement.

In practice, in order to help gifted children in self-contained programs establish positive self-concepts and stimulate their selfconfidence, teachers in gifted programs often give students academic tests equivalent to university entrance tests. When the results are announced, teachers emphasize that their performances are far better than their nongifted peers in mixed regular classes but avoid intraclass comparison among gifted children. This strategy works very well in our gifted programs. It indicates that teacher behavior is very important for the formation of self-concept in gifted children in selfcontained special classes. 
Gender Differences

Gender differences were not part of the original design in our study because there were far fewer gifted girls than gifted boys in most gifted classes. But the results suggest that there were significant gender differences in both gifted and nongifted groups. Interestingly enough, the results of the present study were different from previous findings. Zeidner and Schleyer (1998) found that in mixed-ability classes female students had slightly higher scores than male students in social self-concept; with academic self-concept, the result was reversed. On both social and academic self-concepts, male students had higher scores than female students in gifted classes. Greenwald and Farnham (2000) used implicit association tests to measure the self-esteem and self-concept of university students and did not find significant gender differences. The present study found that the female children's self-concept on all aspects was significantly higher than male children's in many aspects regardless of their ages and intellectual levels.

The discrepancy between the results of our findings and other studies (Zeidner \& Schleyer, 1998; Greenwald \& Farnham, 2000) might be attributed to social conditions, especially child-rearing styles, on child development. In China, because of the "only child" policy, all children who participated in the present study are from only child families. Moreover, no matter how much equality is emphasized, according to traditional Chinese culture, boys are more valued than girls. This bias is reflected in the ratio of males to females from the national population survey. The gender ratio for the whole population is $107 / 100$ (male/female), and, in some areas, especially in remote regions such as Guangxi, the ratio is as high as 112/100. Even in Beijing, the gender ratio is 109/100. The negative effect of gender bias to boys is that, in most families, boys are overprotected because they are considered more "valuable" for maintaining family names, especially in only-child families. As a result of overprotection, boys showed more learned helplessness than girls (Dweck \& Reppucci, 1973), as reflected in the impairment of self-concept. This phenomenon has attracted much attention from the academic community and the public. And, of course, further studies are expected to dig into the mechanisms behind this kind of gender difference phenomenon. Some parenting variables should be involved in fur- 
ther studies in order to detect the relationship between parenting style and the development of self-concept in children

\section{References}

Byrne, B. (1986). Self-concept academic achievement relations: An investigation of dimensionality, stability, and causality. Canadian Journal of Behavioral Science. 18, 173-186.

Chapman, J., \& McAlpine, D. (1988). Students' perceptions of ability. Gifted Child Quarterly, 32, 222-225.

Chen, G., Peters, W., \& Mönks, F. (1997). A comparative study on the self-concept of Chinese and Dutch children with high or average IQs. Psychological Science, 20, 19-26.

Coleman, J. M., \& Fults, B. A. (1982). Self-concept and the gifted classroom: The role of social comparison. Gifted Child 2uarterly, 26, 116-120.

Dweck, C. S., \& Reppucci, D. (1973). Learned helplessness and reinforcement responsibility in children. Journal of Personality and Social Psychology, 25, 109-116.

Elmore, R., \& Zenus, V. (1992). Enhancing social-emotional development of middle school gifted students. Roeper Review, 16, 182-191.

Feldhusen, J. F., \& Hoover, S. M. (1986). A conception of giftedness: Intelligence, self-concept and motivation. Roeper Review, 8, $140-143$.

Festinger, L. (1954). A theory of social comparison processes. Human Relations, 7, 117-140.

Freeman, W. H. (1992). Self as narrative: The place of life history in studying the life span. In R. M. Thomas (Ed.), The self (pp. 15-43). New York: State University of New York Press.

Gao, J. (2000). Teaching theory and practice of humanistic psychology. Educational Science, 1, 48-49.

Greenwald, A. G., \& Farnham, S. D. (2000). Using the implicit association test to measure self-esteem and self-concept. Journal of Personality and Social Psychology, 79, 1022-1038.

Greenwald, A. G., Banaji, M. R., Rudman, L. A., Farnham, S. D., Nosek, B. A., \& Mellott, D. S. (2002). A unified theory of implicit 
attitudes, stereotypes, self-esteem, and self-concept. Psychological Review, 109(1), 3-25.

James, W. (1890). The principles of psychology. London: Macmillan.

Jin, Y. (1996). Making the national urban norms of the Group Intelligence Test for Children (GITC). Psychological Science, 19, 144-149, 191.

Kong, Y., \& Zhu, H. (2005). A decade comparison: Self-concept of gifted \& non-gifted adolescents. International Education Journal, 6, 224-231.

Li, Y., \& Shi, J. (2005). The Big-Fish-Little-Pond Effect: Consideration of the educational placement of gifted children. Advances in Psychological Science, 13, 623-628.

Li, Y., Shi, J., Zhao, D., Wang, Z., Zhuang, J., \& Mao, L. (2004). The difference of nonintellectual factors between gifted and normal children. Chinese Mental Health Journal, 18, 561-563, 568.

Liu, X., Guo, Z., \& Wang, L. (1991). Study on the relations among achievement motivation, self-concept and school achievement of students [In Chinese]. Psychological Science, 2, 19-22.

Marsh, H .W. (1989). Age and sex effects in multiple dimensions of self-concept: Preadolescence to early adulthood. Journal of Educational Psychology, 81, 417-430.

Marsh, H. W. (1994). Using the National Longitudinal Study of 1988 to evaluate theoretical models of self-concept: The selfdescription questionnaire. Journal of Educational Psychology, 86, 439-456.

Marsh, H. W, \& Hau, K.-T. (2003). Big-Fish-Little-Pond effect on academic self-concept: A cross-cultural (26-country) test of the negative effects of academically selective schools. American Psychologist, 58, 364-377.

Marsh, H. W., Chessor, D., Craven, R. G., \& Roche, L. (1995). The effects of gifted and talented programs on academic self-concept: The big fish strikes again. American Educational Research Journal, 32, 285-320.

Marsh, H. W., Hau, K.-T., \& Craven, R. (2004). The Big-Fish-LittlePond Effect stands up to scrutiny. American Psychologist, 59, 269-272.

Marsh, H. W., Richards, G. E., \& Barnes, J. (1986). Multidimensional self-concepts: A long-term follow-up of the effect of participation 
in an Outward Bound program. Personality and Social Psychology Bulletin, 12, 475-492.

Mulcahy, R., Wilgosh, L., \& Peat, D. (1991). The relationship between affect and achievement for gifted, average, and learning disabled students. Gifted Education International, 7, 123-125.

Pyryt, M., \& Mendaglio, S. (1994). The multidimensional self-concept: A comparison of gifted and average-ability adolescents. Journal for the Education of the Gifted, 17, 299-305.

Shavelson, R. J. (1976). Self-concept: Validation of construct interpretations. Review of Educational Research, 46, 407-441.

Shen, M. (2006). Gifted education in Tianyi High School of Jiangsu Province: The pursuit and practice. Gifted Education International, 22(3), 65-69.

Shi, J., \& Zha, Z. (2000). Psychological research on and education of gifted and talented children in China. In K. Heller, F. Mönks, R. Sternberg, \& R. Subotnik (Eds.), International handbook of research and development of giftedness and talent (2nd ed., pp. 757-764). Amsterdam: Elsevier Science.

Shi, J., \& Zhai, J. (2004). Gifted education in primary school. In D. Boothe \& J. Stanley (Eds.), In the eyes of the beholder: Cultural and disciplinary perspectives in giftedness (pp. 119-125). Waco, TX: Prufrock Press.

Tong, J., \& Yewchuk, C. (1996). Self-concept and sex-role orientation in gifted high school students. Gifted Child Quarterly, 40, 15-23.

Vaughn, V. L., Feldhusen, J. F., \& Asher, J. W. (1991). Meta-analyses and review of research on pull-out programs in gifted education. Gifted Child Quarterly, 35, 92-98.

Xin, H. (1990). Education of supernormal children. Beijing, China: People's Education Press.

Xin, S., \& Hao, C. (2003). Review of the relations between children's self-concept and school achievement. Beifang Luncong, 5, 121-125.

Yong, F. L., \& McIntyre, J. D. (1991). Comparison of self-concepts of students identified as gifted and regular students. Perceptual and Motor Skills, 73, 443-446.

Zeidner, M., \& Schleyer, E. J. (1998). The Big-Fish-Little-Pond Effect for academic self-concept, test anxiety, and school grades 
in gifted children. Contemporary Educational Psychology, 24, 305-329.

Zhang, X., He, L., \& Wang, W. (1994). Self-concept of learning disabled students. Journal of Inner Mongolia Ethical Normal University (Philosophical), 4, 70-74.

Zhao, D. (2006, February). The education of the gifted and talented children at Beijing No. 8 Middle School. Paper presented at the Beyond the Standard conference, Bad Boll, Germany.

Zhou, G., \& He, L. (1996). The development of self-concept of 11 - to 15-year-old students. Psychological Development and Education, 3, 37-43.

Zhou, L., \& Zha, Z. (1986). Research on selection of supernormal children for a special class at age 10. Acta Psychologica Sinica, 4, 388-394.

\section{Author Note}

Preparation of this article was supported by Natural Science Foundation ofChina (No.30670716), Frontier Project of Knowledge Innovation Engineering of Chinese Academy of Sciences (No. KFS-2007-10), and Key Project of National Educational Science (No. GBB010921).

The authors would like to express their special appreciation to Dr. Rex Li who spent a lot of time correcting the English of this manuscript. We would also like to express our cordial appreciation to Andrea D. Frazier for her careful checking, correction of English, and helpful assistance in editing our manuscript.

Please address correspondence to Jiannong Shi (shijn@psych. ac.cn). 